\title{
Diet related factors for good glycaemic control among patients with diabetes mellitus in the Teaching Hospital, Batticaloa, Sri Lanka
}

\author{
G. Kisokanth ${ }^{1 *}$, S. Prathapan ${ }^{2}$, J. Indrakumar ${ }^{3}$ and I.M.P.S. Ilankoon ${ }^{4}$ \\ ${ }^{1}$ Department of Supplementary Health Sciences, Faculty of Health-Care Sciences, Eastern University, Batticaloa. \\ ${ }^{2}$ Department of Community Medicine, Faculty of Medical Sciences, University of Sri Jayewardenepura, Gangodawila, Nugegoda. \\ ${ }^{3}$ Department of Medicine, Faculty of Medical Sciences, University of Sri Jayewardenepura, Gangodawila, Nugegoda. \\ ${ }^{4}$ Department of Allied Health Sciences, Faculty of Medical Sciences, University of Sri Jayewardenepura, Gangodawila, Nugegoda.
}

Revised: 12 March 2018; Accepted: 27 April 2018

\begin{abstract}
Ideal dietary practices and diet patterns for the better self-management of diabetes mellitus (DM) remains to be determined. This study was aimed at determining the diet related factors for good glycaemic control among patients with DM attending the Teaching Hospital, Batticaloa, Sri Lanka. A study was conducted among 339 patients with DM in medical clinics. Patients $(\mathrm{n}=77)$ with DM who had fasting blood sugar less than or equal to $110 \mathrm{mgdL}^{-1}$ (cases) and patients $(\mathrm{n}=197)$ with DM who had fasting blood sugar more than or equal to $111 \mathrm{mgdL}^{-1}$ (controls) for at least 3 last consecutive occasions during 6 months were compared. A pre-tested and validated seven-day dietary diary was used. Not consuming at least one serving of fruits in a week (AOR 2.83, $95 \% \mathrm{CI}=1.03-7.76$ ); not consuming bitter gourd (Momordica charantia) at least one tablespoon in a week (AOR 2.23, $95 \% \mathrm{CI}=1.01-4.95$ ); not consuming Kurinja leaves (Gymnema sylvestre) at least one tablespoon in a week (AOR 2.49, $95 \% \mathrm{CI}=1.01-6.17$ ); and consuming any yam (AOR 4.75, $95 \% \mathrm{CI}=1.61-14.07)$; having a bad lunch (AOR 4.64, $95 \% \mathrm{CI}=1.93-11.14$ ) and not following a normal diet pattern for $\geq 4$ days/week (AOR $8.22,95 \% \mathrm{CI}=3.61-18.74)$ were found to be the diet related factors for having poor glycaemic control in the multivariate logistic regression model. Influencing dietary factors on good glycaemic control need to be taken into account for comprehensive management and better outcome of DM.
\end{abstract}

Keywords: Batticaloa, diabetes mellitus, dietary practice, good glycaemic control.

\section{INTRODUCTION}

The prevalence of diabetes mellitus (DM) has become more widespread in developing countries (WHO, 2016). In Sri Lanka, around 1.5 million adults suffer from DM and the numbers are expected to rise up to 2.1 million by the year 2030 (Somasundaram et al., 2013). The recent prevalence of DM for Sri Lankans was $10.3 \%$ and the prevalence was high in urban than rural population (Katulanda et al., 2008). Premaratne et al. (2005) projected a rise of $36 \%$ in the incidence of hospitalisations due to DM in 2010 compared to 2005 among Sri Lankan adults.

Glycaemic control becomes the major therapeutic objective in the prevention of organ damage and other complications among DM patients (Kamuhabwa \& Charles, 2014). Understanding the significance of nutrition therapy, physical activity and regular medication is important for the effective management of blood sugar levels (Ministry of Health, 2014). At the same time, nutrition therapy is an integral part as well as the keystone of diabetes self-management (Folorunso \& Oguntibeju, 2013) in preventing or at least slowing the rate of developing complications (ADA, 2008).

*Corresponding author (kiso.1983@yahoo.com; iD https://orcid.org/0000-0002-5956-4463)

This article is published under the Creative Commons CC-BY-ND License (http://creativecommons.org/licenses/by-nd/4.0/). This license permits use, distribution and reproduction, commercial and non-commercial, provided that the original work is properly cited and is not changed in anyway. 
Further, it is an essential component in the management of DM for reducing new complications (Medagama \& Widanapathirana, 2015).

The adoption of proper dietary habits is essential in the control of DM for the prevention of acute and chronic complications (Queiroz et al., 2010). The diet for patients with DM need not be a separate one or completely different from the normal diet (Kisokanth et al., 2016). Better glycaemic control would be achieved among patients with DM by practicing healthy diet habits through obtaining assistance from a dietitian and/ or a diabetes educator. In addition, adopting healthy eating practices with recommended food for achieving good glycaemic control daily bring both acute and long term effects among DM patients (Jayawardena et al., 2012), and the American Diabetes Association has also recognised it (ADA, 2017). Further, each patient with DM should be actively involved with his or her healthcare provider to develop an individualised dietary plan (ADA, 2017). Physicians are frequently challenged with the task of motivating patients to follow healthy eating for improving the patients' diabetes control and to slow the occurrence of complications of the disease (Fowler, 2010).

The most challenging part of the treatment plan among many DM individuals is determining what to eat and how to eat. There is no ideal conclusive eating pattern that is of benefit to all the individuals with DM (Wheeler et al., 2012). But, some foods need to be added or avoided with the proper food intake patterns for the maintenance of good glycaemic control among the patients with DM. A number of nutritional factors have been found to influence better management of DM (Evert et al., 2014). Better understanding of the dietary factors on the improvement in diabetes control is warranted to help health professionals for successful glycaemic control. Therefore, the study was aimed at determining the diet related factors for good glycaemic control among patients with DM in the Teaching Hospital, Batticaloa.

\section{METHODOLOGY}

\section{Study design}

This unmatched (1:2) case control study was conducted among patients with DM at the Medical Clinic, Teaching Hospital, Batticaloa. This study compared a group of patients with DM who have had good glycaemic control (cases) with a group of patients with DM who have had poor glycaemic control (controls) with respect to a number of diet related factors. A case in this study was defined as a patient with DM who had fasting blood sugar less than or equal to $110 \mathrm{mgdL}^{-1}$ in at least last 3 consecutive occasions during the last 6 months and control was defined as a patient with DM who had fasting blood sugar more than or equal to $111 \mathrm{mgdL}^{-1}$ in at least last 3 consecutive occasions during the last 6 months.

Fasting blood glucose of $110 \mathrm{mgdL}^{-1}$ or less was considered as better control of glycaemia among patients with DM (Ministry of Health Care and Nutrition, 2007). Further, the American Association of Clinical Endocrinologists (AACE) and the American College of Endocrinology (ACE) emphasised that fasting blood glucose should be targeted less than $110 \mathrm{mgdL}^{-1}$ (AACE/ ACE, 2015) and levels more than $110 \mathrm{mgdL}^{-1}$ were associated with substantial cardiovascular risk.

\section{Study participants and size}

The participants included in this study were patients who have lived at least for 2 years in the Batticaloa District with DM, diagnosed at least 2 years ago, treated with oral hypoglycaemic agents or insulin or both or diet alone, and age of above 30 years. Patients who refused to give consent for participating in the study, patients with gestational DM and patients having any physical discomfort or pain due to surgery or ulcers when attending the medical clinic were excluded from the study. The sample size was calculated for unequal case control ratio (Schlesselman \& Schneiderman, 1982). Expose rate among controls was considered as $50 \%$ and odds ratio was 2. Calculated sample size for case was 113 and the control was 226.

\section{Study instrument and validation}

A validated pre-tested seven-day dietary diary was used by the author for obtaining the information on each patient's dietary practices along with their sociodemographic details. Each patient was asked to fill the seven-day dietary diary with the food and beverages that would be consumed in 3 main meals and 2 snacks for the next 7 days.

The seven-day dietary diary was prepared in English initially. Then, it was translated to Tamil language by two independent language experts, where they were requested by the author to retain the original structure and content as much as possible. The translated seven-day dietary diary was compared by the two bilingual English - Tamil experts. The author discussed some variations with the two experts and consensual alterations were made. The agreed Tamil version of the seven-day dietary diary was 
translated back to English by the two bilingual English - Tamil experts. The back-translated version was again checked with the original version of seven-day dietary diary by the author for consistency and accuracy of the information. However, only a few discrepancies were found and were corrected again after discussions with the expert translators. Judgemental validity was carried out to assess the validity of the Tamil version of the sevenday dietary diary. The Tamil version and the original English version of the seven-day dietary diary were sent to three nutritionists who were treating patients with DM. These nutritionists were fluent in reading, writing and speaking the Tamil and English Languages. All experts did some overall changes especially on the wording and the understanding in the local context. These changes were attended to by the author.

\section{Pre-testing of study instrument}

The seven-day dietary diary was pre-tested for acceptability, comprehension and to assess the clarity and suitability of the words used, at the Base Hospital, Kaluwanchikudy, Sri Lanka. Modifications were made based on the clarifications. After that, pilot testing was conducted at the same hospital to identify the potential problems in carrying out the study and to assess the time needed to carry out the study properly.

\section{Data collection}

The administration of the Tamil version of the seven-day dietary diary was carried out by the trained data collector after obtaining socio-demographic information. The data collection was carried out in Medical Clinics, Teaching Hospital, Batticaloa on clinic days from Monday to Friday. The nurse in-charge of the clinic recruited the cases and controls from clinic according to the inclusion and exclusion criteria of the study. These patients were sent to the data collector. The data collector was not aware whether the patient is a case or a control. Repetition was avoided by using the patient's clinic registration number and clarified with the patient while selecting. At the time of recruitment, written consent was obtained from each participant. An information sheet outlined the objectives as well as the maintenance of anonymity for research purposes. None of the patients refused to participate in the study. Each patient was given a seven-day dietary diary to fill the type of food and beverages they would consume for 3 main meals and 2 snacks every day during the following 7 days. This seven-day dietary diary was given along with a self-addressed stamped envelope of the author. Each patient was advised on how to fill the dietary diary and requested to post it on the $8^{\text {th }}$ day.

\section{Glycaemic index (GI) and portion size determination}

The foods or combination of foods for breakfast and dinner from the seven-day dietary diary was assigned to one of the following three categories; low, medium and high glycaemic index, based on previous studies carried out in Sri Lanka (Pirasath et al., 2010; 2013; 2015a; 2015b; Ministry of Health, 2014). Portion size of fruit consumed by the participants was determined according to Jayawardena et al. (2012). A good lunch was defined as $1 / 4$ plate of rice with 3 vegetable curries ( $1 / 2$ plate) and 1 piece of fish or chicken or an egg (protein component $1 / 4$ plate). A normal diet pattern per day was defined as 3 main meals plus 2 healthy snacks per day (Ministry of Health, 2014).

\section{Statistical analysis}

The analysis for identifying factors associated with good glycaemic control started with simple univariate analysis followed by multivariate logistic regression using statistical package for the social sciences (SPSS) software version 20 .

Unadjusted odds ratio (OR) with $95 \%$ confidence interval (CI) of the results was used to test the significance of the differences observed. Odds ratio is a better index of assessing the casual relationship between variables and diseases as it is the ratio of the odds among cases to the odds among the controls (Hennekens \& Buring, 1987). A probability of $<0.05$ was considered as statistically significant.

Multivariate analysis was used to control the independent and intervening variables upon one another (confounding). Covariates that were insignificant at the multivariate level were dropped consecutively from the model after careful assessment of confounding. The final model was selected on the basis of theoretical and statistical significance of factors associated with good glycaemic control. The type 1 error rate was set at 0.05 . The model estimates are presented with the adjusted odds ratios (AOR) and $95 \% \mathrm{CI}$.

\section{Ethical clearance}

Ethical approval (ERC No: 627/12) was obtained from the Ethics Review Committee, Faculty of Medical Sciences, University of Sri Jayewardenepura, Sri Lanka. Permission was obtained from the Director, Teaching Hospital, Batticaloa prior to the study. The study procedure was explained in detail and written informed consent was obtained from all the participants. Data obtained were kept under lock and key. Privacy and 
confidentiality of the subjects were ensured throughout the study. The research findings were used for academic purposes only.

\section{RESULTS AND DISCUSSION}

\section{Socio-demographic details of the participants}

A total of 339 patients were included (113 good glycaemic control and 226 poor glycaemic control) in this study. The response rate was $80.8 \%(\mathrm{n}=274)$. Among them, 77 $(68.1 \%)$ patients were in good glycaemic control while
197 (87.2 \%) patients were in poor glycaemic control. Two hundred and seventy four (274) participants were interviewed, of which 197 (71.9\%) were females. Nearly $47 \%$ of participants were in the age of $\geq 60$ years. More than half of the participants in both groups had obtained school education up to GCE Ordinary Level $(\mathrm{O} / \mathrm{L})$. Most of the participants (72.6\%) were married. Further, $76.3 \%$ of the participants were physically inactive/ had no employment. None of the sociodemographic factors showed a statistically significant difference between the two groups $(p>0.05)$ except place of residence $(p=0.02)$ (Table 1).

Table 1: Socio-demographic characteristics of the participants

\begin{tabular}{|c|c|c|c|c|}
\hline $\begin{array}{l}\text { Socio-demographic } \\
\text { characteristics }\end{array}$ & $\begin{array}{c}\text { Poor } \\
\text { glycaemic control } \\
(\mathrm{n}=197) \mathrm{n}(\%)\end{array}$ & $\begin{array}{c}\text { Good } \\
\text { glycaemic control } \\
(\mathrm{n}=77) \mathrm{n}(\%)\end{array}$ & $\begin{array}{c}\text { Total } \\
(\mathrm{n}=274) \\
\mathrm{N}(\%)\end{array}$ & $\mathrm{p}$ value \\
\hline Gender & & & & 0.06 \\
\hline Male & $49(24.9)$ & $28(36.4)$ & $77(28.1)$ & \\
\hline Female & $148(75.1)$ & $49(63.6)$ & $197(71.9)$ & \\
\hline Age (years) & & & & 0.77 \\
\hline $30-39$ & $7(3.6)$ & $3(3.9)$ & $10(3.6)$ & \\
\hline $40-49$ & $25(12.7)$ & $12(15.6)$ & $37(13.5)$ & \\
\hline $50-59$ & $74(37.5)$ & $24(31.2)$ & $98(35.8)$ & \\
\hline$\geq 60$ & $91(46.2)$ & $38(49.1)$ & $129(47.1)$ & \\
\hline Education level & & & & 0.73 \\
\hline No schooling & $13(4.6)$ & $4(5.2)$ & $17(6.2)$ & \\
\hline Up to grade 5 & $46(23.4)$ & $15(19.5)$ & $61(22.3)$ & \\
\hline $\mathrm{Up}$ to $\mathrm{O} / \mathrm{L}$ & $117(59.4)$ & $45(58.4)$ & $162(59.1)$ & \\
\hline Up to $\mathrm{A} / \mathrm{L}$ and above & $21(10.7)$ & $13(16.9)$ & $34(12.4)$ & \\
\hline Monthly income (Rs) & & & & 0.12 \\
\hline Low $(<10,000)$ & $152(77.2)$ & $55(71.4)$ & $207(75.5)$ & \\
\hline Middle and above $(\geq 10,000)$ & $45(22.8)$ & $22(28.6)$ & $67(24.5)$ & \\
\hline Marital status & & & & 0.59 \\
\hline Married & $146(74.1)$ & $53(68.8)$ & $199(72.6)$ & \\
\hline Unmarried & $10(5.1)$ & $5(6.5)$ & $15(5.5)$ & \\
\hline Living together & $1(0.5)$ & $0(0.0)$ & $1(0.4)$ & \\
\hline Separated/ divorced & $3(1.5)$ & $2(2.6)$ & $5(1.8)$ & \\
\hline Widowed & $37(18.8)$ & $17(22.1)$ & $54(19.7)$ & \\
\hline Employment & & & & 0.20 \\
\hline Physically active & $42(21.3)$ & $23(29.9)$ & $65(23.7)$ & \\
\hline Physically inactive & $155(78.7)$ & $54(70.1)$ & $209(76.3)$ & \\
\hline Place of residence & & & & 0.01 \\
\hline Urban & $129(65.5)$ & $37(48.1)$ & $166(60.6)$ & \\
\hline Rural & $68(34.5)$ & $40(51.9)$ & $108(39.4)$ & \\
\hline
\end{tabular}


Factors related to consumption of fruits and
vegetables

The importance of adopting healthy eating habits has been identified as an essential measure for the prevention of acute and chronic complications in patients with DM (ADA, 2017). However, a few studies have evaluated the impact of eating habits in the metabolic control of patients with DM. In this study, multivariate logistic regression was applied to the control for confounding factors and to predict the variables for poor glycaemic control.

In the present study, patients who did not consume fruits (at least one serving in a week) were nearly at 3 times higher risk of getting poor glycaemic control than those who ate fruits except mango and jackfruit at least one serving in a week (AOR 2.83, $95 \% \mathrm{CI}=1.03-7.76)$. This finding was supported by Thompson et al. (2012) that showed consumption of a high-fruit diet had a tendency towards improvement of glycosylate haemoglobin (HbA1c) in patients with
DM. Also, avoiding high glycaemic index (GI) fruits especially, dates, jackfruit and mango would improve the glycaemic control among DM patients (Ministry of Health, 2014). Further, a Canadian study confirmed that low GI fruit consumption was significantly associated with lower HbAlc among DM patients (Jenkins et al., 2011). However, consumption of fruits in day-to-day life among the study participants was very minimal. It was supported by a Sri Lankan study carried out among DM patients that stated only one fourth of the participants consumed the recommended portion of fruits daily and $33 \%$ did not consume fruits at all (Medagama \& Widanapathirana, 2015).

In this study, patients who had consumed any yam, specially potato (Solanum tuberosum) and manioc (Manihot esculenta) were nearly at 5 times higher risk of getting poor glycaemic control than those who had not consumed potato and/or manioc at all (AOR 4.75, $95 \%$ $\mathrm{CI}=1.61-14.07)$ (Table 2). The habitual consumption of yams has adversely affected the glycaemic control of study participants. Those who had received advice from

Table 2: Fruits and vegetables related factors between poor and good glycaemic controls

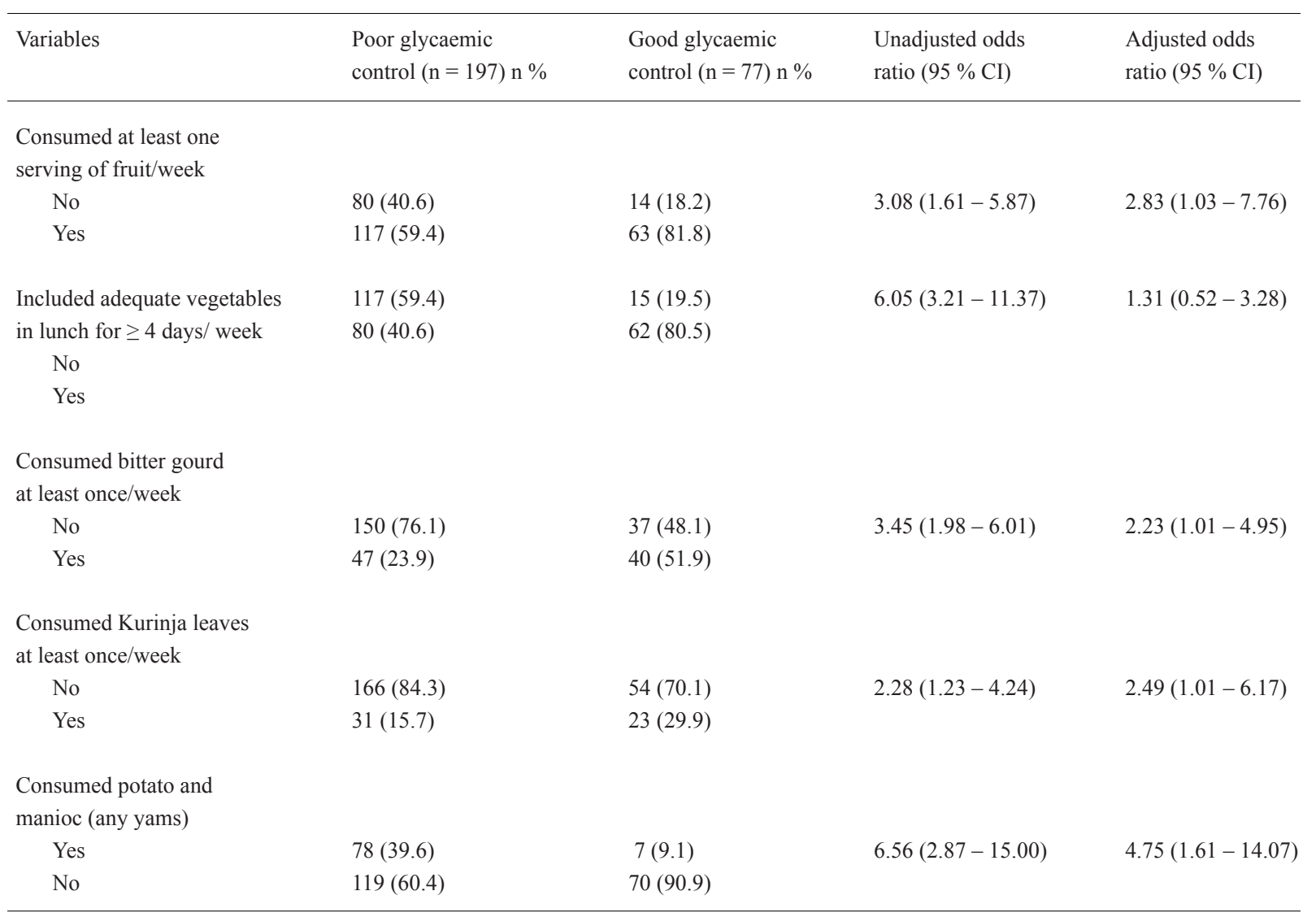


the healthcare provider at the clinic had not consumed any root vegetables at all, especially manioc and potato and obtained good glycaemic control. This is mainly due to the reason that manioc and potato have higher glycaemic index $(>75 \%)$, which would increase the blood glucose level (Ministry of Health, 2014; Pirasath et al., 2015b).

Further, those who had not added bitter gourd (Momordica charantia) in their meal at least once in a week were nearly at 2 times higher risk of getting poor glycaemic control than those who had added bitter gourd in their meals once in a week (at least 1 tablespoon) (AOR $2.23,95 \% \mathrm{CI}=1.01-4.95)$. Similarly, patients who had not included Kurinja leaves (Gymnema sylvestre) in their meals at least once in a week were at 2.5 times higher risk of getting poor glycaemic control than those who had added Kurinja leaves in their meals at least once in a week (at least 1 tablespoon) (AOR 2.49, $95 \%$ $\mathrm{CI}=1.01-6.17)$. The consumption of bitter gourd was found to be effective in obtaining good glycaemic control in this study. Similarly, several animal studies proved that bitter gourd has a significant effect on the reduction of blood glucose level and increased plasma insulin concentration (Ahmad et al., 1999; Vikrant et al., 2001; Kar et al., 2003). Another study carried out in Sri Lanka among diabetic adults stated that most participants came up with a list of 'special' food items that had helped them to control blood sugar in addition to their medications such as fenugreek seeds ('Uluhal'), bitter gourd and curry leaves (Ranasinghe et al., 2015). Further, it was mentioned in a study conducted in Pakistan among patients with diabetes that majority of the participants believed that not consuming root vegetables while

Table 3: Diet pattern related factors between good and poor glycaemic controls

\begin{tabular}{|c|c|c|c|c|}
\hline Variables & $\begin{array}{c}\text { Poor glycaemic } \\
\text { control }(\mathrm{n}=197) \\
\mathrm{n}(\%)\end{array}$ & $\begin{array}{c}\text { Good glycaemic } \\
\text { control }(\mathrm{n}=77) \\
\mathrm{n}(\%)\end{array}$ & $\begin{array}{l}\text { Unadjusted odds } \\
\text { ratio (OR) } \\
(95 \% \mathrm{CI})\end{array}$ & $\begin{array}{l}\text { Adjusted odds } \\
\text { ratio }(\mathrm{AOR}) \\
\quad(95 \% \mathrm{CI})\end{array}$ \\
\hline \multicolumn{5}{|l|}{$\begin{array}{l}\text { Type of rice use } \\
\text { for } \geq 4 \text { days/week }\end{array}$} \\
\hline White & $89(45.2)$ & $14(18.2)$ & $3.71(1.95-7.06)$ & $1.93(0.82-4.57)$ \\
\hline Red & $108(54.8)$ & $63(81.8)$ & & \\
\hline \multicolumn{5}{|c|}{$\begin{array}{l}\text { Type of food consumed for } \\
\text { breakfast for } \geq 4 \text { days/week }\end{array}$} \\
\hline Medium GI food & $60(30.5)$ & $10(13.0)$ & $2.93(1.41-6.09)$ & $2.46(0.93-6.51)$ \\
\hline Low GI food & $137(69.5)$ & $67(87.0)$ & & \\
\hline \multicolumn{5}{|l|}{$\begin{array}{l}\text { Type of lunch used } \\
\text { for } \geq 4 \text { days/week }\end{array}$} \\
\hline $\mathrm{Bad}$ & $159(80.7)$ & $27(35.1)$ & $7.75(4.31-13.93)$ & $4.64(1.93-11.14)$ \\
\hline Good & $38(19.3)$ & $50(64.9)$ & & \\
\hline \multicolumn{5}{|c|}{$\begin{array}{l}\text { Type of food used for } \\
\text { dinner for } \geq 4 \text { days/week }\end{array}$} \\
\hline Medium GI food & $79(40.1)$ & $15(19.5)$ & $2.77(1.47-5.21)$ & $1.31(0.56-3.07)$ \\
\hline Low GI food & $118(59.9)$ & $62(80.5)$ & & \\
\hline \multicolumn{5}{|l|}{$\begin{array}{l}\text { Normal diet pattern } \\
\text { for } \geq 4 \text { days/week }\end{array}$} \\
\hline No & $168(8.3)$ & $26(33.8)$ & $11.36(6.14-21.02)$ & $8.22(3.61-18.74)$ \\
\hline Yes & $29(14.7)$ & $51(66.2)$ & & \\
\hline \multicolumn{5}{|l|}{ Consumption of sugar } \\
\hline Yes & $136(69.0)$ & $31(40.3)$ & $3.31(1.92-5.71)$ & $0.96(0.43-2.16)$ \\
\hline No (Never) & $61(31.0)$ & $46(59.7)$ & & \\
\hline
\end{tabular}


regular use of bitter gourd could manage diabetes well (Rafique et al., 2006). Furthermore, another Sri Lankan study found that bitter gourd was the most frequently consumed herbal remedy (65.8\%) for better glycaemic control among DM patients (Medagama et al., 2014).

\section{Diet pattern related factors}

In the present study, patients who consumed a bad lunch for 4 or more days per week were nearly at 5 times higher risk of getting poor glycaemic control than those who had consumed a good lunch for 4 or more days per week (AOR 4.64, $95 \% \mathrm{CI}=1.93$ - 11.14). In addition, patients who had not followed a normal diet pattern for 4 or more days were at 8 times higher risk of getting poor glycaemic control than those who had a normal diet pattern for 4 or more days per week (AOR 8.22, $95 \%$ $\mathrm{CI}=3.61-18.74)($ Table 3$)$.

In the present study, a good glycaemic control was observed among those who consumed adequate vegetables for their lunch (good lunch) for most of the days in a week when compared to their counterparts. Similarly, it was emphasised by Medagama and Widanapathirana (2015), that adding both fruits and vegetables to a rice meal have shown beneficial effects on glycaemic control among type 2 diabetes mellitus (T2DM) patients. Further, a study by Kameyama et al. (2014) proved that postprandial glucose has been reduced by adding vegetables to rice-based meals among healthy Japanese men. It could be explained that the daily intake of green leafy vegetables and the quantity consumed were inadequate to obtain beneficial effects among Sri Lankan DM patients (Senadheera et al., 2016). Further, patients who had consumed low glycaemic index (GI) food for their breakfast and dinner for most of the days per week had the chance of having good glycaemic control among the study participants. A meta-analysis study emphasised that there was a significant reduction in $\mathrm{HbAlc}$ levels among those who had received low GI diets compared to high GI diets (Thomas \& Elliott, 2010), and a Sri Lankan study concluded lower GI diets as better choices for better glycaemic control (Pirasath et al., 2015a). It could be explained that low GI foods supply glucose gradually into the bloodstream, which thus contributes to improve the glycaemic control (Jenkin et al., 1981). At the same time, low GI diets increase insulin sensitivity by minimising fluctuations in blood glucose levels and reducing the secretion of insulin over the day (Crapo et al., 1977). Thus, adding a low GI diet appears to be an effective method to improve glycaemic control among DM patients and would be considered as a part of management.

In addition, patients who followed the normal diet pattern also achieved good glycaemic control. This was evident in a study where adequate glycaemic control was achieved among diabetes patients who had the habit of eating breakfast and dinner regularly (Orbey et al., 2007). Also, eating at regular intervals with 3 main meals and 2 healthy snacks helps to prevent high blood glucose among patients with diabetes (Ministry of Health, 2014).

In addition, more effective self-management of DM would result from the mindfulness training of the patients on what they should or should not eat (Sowattanangoon et al., 2009). Although there is no ideal recommended eating pattern for successful glycaemic control, there are a few foods and dietary practices to be followed. When recommending foods and dietary practices, the culture, knowledge, health beliefs and availability and affordability of the foods should be considered.

\section{CONCLUSION}

A good glycaemic control is possible among DM patients by practicing the recommended dietary patterns. Consuming at least one serving of recommended fruits in a week, consuming bitter gourd at least one tablespoon in a week, consuming Kurinja leaves at least one tablespoon in a week, and not consuming any yams at all, were found to be significant dietary related factors for having good glycaemic control. Further, having a good lunch and a normal diet pattern for $\geq 4$ days/week were also found to be significant dietary related factors for having good glycaemic control. At present, the compliance to recommended dietary practices is poor. Adherence to the acceptable dietary practices contributes to better selfmanagement among diabetic patients through enabling healthcare workers.

\section{Conflict of interests}

The authors declare that there is no conflict of interests regarding the publication of this study

\section{Acknowledgement}

The authors thank all the patients participated in this study, and the Director, Consultant Physicians and Nurse in-Charge of the Medical Clinic, Teaching Hospital, Batticaloa. 


\section{REFERENCES}

Ahmad N., Hassan M.R., Halder H. \& Bennoor K.S. (1999). Effects of Momordica charantia (Karolla) extracts on fasting and postprandial serum glucose levels in NIDDM patients. Bangladesh Medical Research Council Bulletin 25(1): $11-13$.

American Association of Clinical Endocrinologists and American College of Endocrinology (AACE/ACE) (2015). $A A C E / A C E$ Guidelines. Clinical practice guidelines for developing a diabetes mellitus comprehensive care plan. Endocrine Practice 21(1): 1 - 89.

American Diabetes Association (ADA) (2008). Nutritional recommendations and intervention for Diabetes. Diabetes Care 31(1): S61 - S78.

American Diabetes Association (ADA) (2017). Standards of medical care in diabetes: introduction. Diabetes Care 40(1): S1 - S80.

Crapo P.A., Reaven G. \& Olefsky J. (1977). Postprandial plasma-glucose and insulin responses to different complex carbohydrates. Diabetes 26(12): 1178 - 1183.

DOI: https://doi.org/10.2337/diab.26.12.1178

Evert A.B et al. (11 authors) (2014). Nutrition therapy recommendations for the management of adults with diabetes. Diabetes Care 37(1): S120 - S142.

DOI: https://doi.org/10.2337/dc14-S120

Folorunso O. \& Oguntibeju O. (2013). The role of nutrition in the management of diabetes mellitus. Available at https://www.intechopen.com/books/diabetes-mellitusinsights-and-perspectives/the-role-of-nutrition-in-themanagement-of-diabetes-mellitus, Accessed 22 August 2016.

Fowler M.J. (2010). Diagnosis, classification, and lifestyle treatment of diabetes. Clinical Diabetes 28(2): $79-86$.

DOI: https://doi.org/10.2337/diaclin.28.2.79

Handelsman Y. et al. (34 authors) (2015). American Association of Clinical Endocrinologists and American College of Endocrinology - clinical practice guidelines for developing a diabetes mellitus comprehensive care plan. Endocrine Practice 21(1): 1 - 87.

Hennekens C.H. \& Buring J. (1987). Epidemiology in Medicine, $1^{\text {st }}$ edition. Little, Brown and Co., Boston, USA.

Jayawardena R., Byrne N.M., Soares M.J., Katulanda P. \& Hills A.P. (2012). Food consumption of Sri Lankan adults: an appraisal of serving characteristics. Public Health Nutrition 16(4): 653 - 658.

DOI: https://doi.org/10.1017/S1368980012003011

Jenkins D.J., Wolever T.M., Taylor R.H., Barker H., Fielden H., Baldwin J.M., Bowling A.C., Newman H.C., Jenkins A.L. \& Goff D.V. (1981). Glycaemic index of foods: a physiological basis for carbohydrate exchange. American Journal of Clinical Nutrition 34(3): 362 - 366.

DOI: https://doi.org/10.1093/ajcn/34.3.362

Jenkins D.J. et al. (17 authors) (2011). The relation of low glycaemic index fruit consumption to glycaemic control and risk factors for coronary heart disease in type 2 diabetes. Diabetologia 54(2): $271-279$.

DOI: https://doi.org/10.1007/s00125-010-1927-1
Kameyama N., Maruyama C., Matsui S., Araki R., Yamada Y. \& Maruyama T. (2014). Effects of consumption of main and side dishes with white rice on postprandial glucose, insulin, glucose-dependent insulinotropic polypeptide and glucagon-like peptide-1 responses in healthy Japanese men. British Journal of Nutrition 111(9): 1632 - 1640.

DOI: https://doi.org/10.1017/S0007114513004194

Kamuhabwa A.R. \& Charles E. (2014). Predictors of poor glycaemic control in type 2 diabetic patients attending public hospitals in Dar es Salaam. Drug Healthcare Patient Safety 6: $155-165$.

DOI: https://doi.org/10.2147/DHPS.S68786

Kar A., Choudhary B.K. \& Bandyopadhyay N.G. (2003). Comparative evaluation of hypoglycaemic activity of some Indian medicinal plants in alloxan diabetic rats. Journal of Ethnopharmacology 84(1): 105 - 108.

Katulanda P., Constantine G.R., Mahesh J.G., Sheriff R., Seneviratne R.D., Wijeratne S., Wijesuriya M., McCarthy M.I., Adler A.I. \& Matthews D.R. (2008). Prevalence and projections of diabetes and pre-diabetes in adults in Sri Lanka-Sri Lanka diabetes, cardiovascular study (SLDCS). Diabetic Medicine 25(9): 1062 - 1069.

DOI: https://doi.org/10.1111/j.1464-5491.2008.02523.x

Kisokanth G., Prathapan S., Indrakumar J. \& Joseph J. (2016). Self-management of diabetes mellitus among Tamils in the Batticaloa District, Sri Lanka: a qualitative study. Pakistan Journal of Nutrition 15(5): 455 - 460. DOI: https://doi.org/10.3923/pjn.2016.455.460

Medagama A.B., Bandara R., Abeysekera R.A., Imbulpitiya B. \& Pushpakumari T. (2014). Use of complementary and alternative medicines (CAMs) among type 2 diabetes patients in Sri Lanka: a cross sectional survey. BMC Complementary and Alternative Medicine 14: 374. DOI: https://doi.org/10.1186/1472-6882-14-374

Medagama A. \& Widanapathirana H. (2015). A traditional Asian diet modified to meet nutritional requirements of diabetes, has anything changed? A cross-sectional dietary survey. BMC Nutrition 1: 8.

Ministry of Health (2014). Dietary guidelines and nutrition therapy for specific diseases. Available at https://www. google.lk/webhp? sourceid=chrome-instant\&rlz=1C1CH$Z L \_$enLK682LK682\&ion $=1 \&$ esp $v=2 \& i e=U T F \& \# q=D i$ etary + Guidelines $+\% 26+$ Nutrition + Therapy + for + Specific +Diseases, Accessed 20 March 2016.

Ministry of Health Care and Nutrition (2007). Clinical practice guideline: management of diabetes mellitus, Sri Lanka. Available at http://www.slcog.lk/img/guidelines/ Other\%20national\%20Gidelines/Physicians/Book\%201/ Management\%20of\%20Diabetes\%20Mellitus.pdf, Accessed 22 August 2016.

Orbey N.C., Margeirsdottir H.D., Brunborg C., Andersen L.F. \& Dahl-Jorgensen K. (2007). The influence of dietary intake and meal pattern on blood glucose control in children and adolescents using intensive insulin treatment. Diabetologia 50(10): 2044 - 2051.

DOI: https://doi.org/10.1007/s00125-007-0775-0

Pirasath S., Balakumar S. \& Arasaratnam V. (2015a). Glycaemic index of Sri Lankan meals. Journal of Blood Disorders and Transfusion 6: 254. 
DOI: https://doi.org/10.4172/2155-9864.1000254

Pirasath S., Balakumar S. \& Arasaratnam V. (2015b). Glycaemic index of traditional foods in northern Sri Lanka. Endocrinology and Metabolic Syndrome 4: 154.

Pirasath S., Thayaananthan K., Balakumar S. \& Arasaratnam V. (2010). Effect of dietary curries on the glycaemic index. Ceylon Medical Journal 55(4): 118 - 122.

DOI: https://doi.org/10.4038/cmj.v55i4.2629

Pirasath S., Thayananthan K., Balakumar S. \& Arasaratnam V. (2013). Including side dishes to traditional main meals alter the glycaemic index. Sri Lanka Journal of Diabetes, Endocrinology and Metabolism 3: $12-18$.

Premaratne R., Amarasinghe A. \& Wickramasinghe A.R. (2005). Hospitalization trends due to selected noncommunicable diseases in Sri Lanka 2005 - 2010. Ceylon Medical Journal 50(2): 51 - 54.

DOI: https://doi.org/10.4038/cmj.v50i2.1568

Queiroz K.C., Rookie I.S. \& Alfenas R.C.G. (2010). Association between nutritional factors and glycaemic control in children and adolescents with type 1 diabetes. Arquivos Brasileiros de Endocrinologia and Metabologia 54(3): $319-325$.

DOI: https://doi.org/10.1590/S0004-27302010000300011

Rafique G., Azam S.I. \& White F. (2006). Diabetes knowledge, beliefs and practices among people with diabetes attending a university hospital in Karachi, Pakistan. Eastern Mediterranean Health Journal 12(5): 590 - 598.

Ranasinghe P., Pigera A.S.A.D., Ishara M.H., Jayasekara L.M.D.T., Jayawardena R. \& Katulanda P. (2015). Knowledge and perceptions about diet and physical activity among Sri Lankan adults with diabetes mellitus: a qualitative study. BMC Public Health 15: 1160. DOI: https://doi.org/10.1186/s12889-015-2518-3

Schlesselman J.J. \& Schneiderman M.A. (1982). Case control studies - design, conduct, analysis. Journal of Occupational Medicine 24(11): 879.
Senadheera S.P.A.S., Ekanayake S. \& Wanigatunge C. (2016). Dietary habits of type 2 diabetes patients: variety and frequency of food intake. Journal of Nutrition and Metabolism. 2016: Article ID 7987395.

DOI: https://doi.org/10.1155/2016/7987395

Somasundaram N.P. et al. (27 authors) (2013). Diabetes mellitus: glucose control. Sri Lanka Journal of Diabetes, Endocrinology and Metabolism 3(1): 45 - 57.

Sowattanangoon N., Kotchabhakdi N. \& Petrie K.J. (2009). The influence of Thai culture on diabetes perceptions and management. Diabetes Research and Clinical Practice 84(3): $245-251$.

DOI: https://doi.org/10.1016/j.diabres.2009.02.011

Thomas D.E. \& Elliott E.J. (2010). The use of low-glycaemic index diets in diabetes control. British Journal of Nutrition 4(6): $797-802$.

DOI: https://doi.org/10.1017/S0007114510001534

Thompson S.V., Winham D.M. \& Hutchins A.M. (2012). Bean and rice meals reduce postprandial glycaemic response in adults with type 2 diabetes: a cross-over study. Nutrition Journal 11(1): 23.

DOI: https://doi.org/10.1186/1475-2891-11-23

Vikrant V., Grover J.K., Tondon N., Rathi S.S. \& Gupta N. (2001). Treatment with extracts of Momordica charantia and Eugenia jambolana prevents hyperglycemia and hyperinsulinemia in fructose fed rats. Journal of Ethnopharmacology 76(2): 139 - 143.

Wheeler M.L., Dunbar S.A., Jaacks L.M., Karmally W., Mayer-Davis E.J., Wylie-Rosett J. \& Yancy Jr W.S. (2012). Macronutrients, food groups, and eating patterns in the management of diabetes. Diabetes Care 35(2): $434-445$. DOI: https://doi.org/10.2337/dc11-2216

World Health Organisation (WHO) (2016), Global report on Diabetes Mellitus (pdf) Available at http://apps.who.int/ iris/bitstream/10665/204871/1/9789241565257_eng.pdf, Accessed 20 January 2017. 